\title{
Pre- versus postdecisional deliberation and goal commitment: The positive effects of defensiveness
}

\author{
Gergana Y. Nenkov ${ }^{a, *}$, Peter M. Gollwitzer ${ }^{b, c}$ \\ a Carroll School of Management, Boston College, 140 Commonwealth Avenue, Chestnut Hill, MA 02467, USA \\ b Department of Psychology, New York University, New York, USA \\ c Department of Psychology, University of Konstanz, Konstanz, Germany
}

\begin{abstract}
A B S T R A C T
Building on Gollwitzer's (1990) mindset theory of action phases, it is proposed that the effects of assigned balanced deliberation on subsequent goal commitment are moderated by people's pre- versus postdecisional status. A balanced deliberation and impartial assessment of pros and cons is expected to reduce goal commitment in predecisional individuals, whereas a distortion of the assigned balanced deliberation and a partial focus on the pros of goal pursuit should defend and strengthen goal commitment in postdecisional individuals. Indeed, in Study 1, assigned deliberation on the pros and cons of pursuing a focal goal promoted stronger reported goal commitment in participants who had decided to pursue this goal, but reduced goa commitment for people who had not yet made such a decision. In Study 2, the same pattern of results emerged when goal commitment was indicated by planning to act on the goal. Study 3 replicated findings using a different decision status manipulation and goal persistence as a measure of commitment. Finally results of Study 4 suggested that the increase in commitment produced by defensive postdecisiona deliberation is consequential as it was found to drive real-life behavior by promoting goal-directed action. Moreover, Studies 2, 3, and 4 explored the underlying process and provided evidence that it is the partial focus on the pros of goal pursuit, meant to defend existing goal commitment, that drives postdecisional deliberation's strengthening effects on goal commitment. Implications for mindset theory, goal commitment theory, and decision making are discussed.
\end{abstract}

\section{Introduction}

Many academic studies, self-help books, and old sayings advise people to think before they act, look before they leap, and measure twice before cutting once. Indeed, engaging in a thorough predecision deliberation of the pros and cons of pursuing a potential goal or not has been found to have beneficial effects like reducing people's illusions of control (Gollwitzer \& Kinney, 1989), engendering impartial processing of information (Beckmann \& Gollwitzer, 1987), suppressing illusionary positive self-perceptions (Taylor \& Gollwitzer, 1995), increasing forecast accuracy (Gagne \& Lydon, 2001a), and increasing receptivity to available information (Heckhausen \& Gollwitzer, 1987). However, the question arises as to whether thorough deliberation on the pros and cons of a potential goal is always beneficial for goal pursuit.

The authors would like to thank Linda Salisbury and Karen Page Winterich for the helpful comments on earlier versions of this manuscript, and Feisal Murshed for the help with data collection. The authors gratefully acknowledge the financial support provided by Boston College.

* Corresponding author. Fax: +16175526677.

E-mail address: gergana.nenkov@bc.edu (G.Y. Nenkov)
In their examination of the effects of action phase mindsets on behavior, Armor and Taylor (2003) pointed to the possibility that prolonged deliberation might have costs as well as benefits and suggested that even though a thorough consideration of pros and cons may reduce the likelihood of making a rushed step, it might also make one less likely to take any steps, thus slowing relevant goal-directed action. In the present research, we will ask whether such increased undecisiveness will indeed occur when people engage in predecisional deliberation. Moreover, we will raise the question of whether this consequence can also be expected when balanced deliberation is assigned after a goal decision has already been made. The latter would be particularly costly as people might fail in striving for those goals they have decided to attain.

In the current paper, we propose that the consequences accruing from assigned deliberation of pros and cons of a goal decision depend on when such deliberation occurs. If deliberation occurs prior to a goal decision we expect it to be balanced and impartial, leading to reduced goal commitment. However, if it occurs after a goal decision has been made, we expect it to be defensively partial to the chosen goal, leading to enhanced goal commitment. As such, we propose that postdecisional individuals who are assigned balanced deliberation would defend their existing commitment by 
distorting deliberation and focusing disproportionately on the pros of goal pursuit.

\section{Action phases and mindsets}

The mindset model of action phases (Gollwitzer, 1990; Heckhausen \& Gollwitzer, 1987) takes a temporal (horizontal) perspective on the course of action and suggests that the predecision phase, which involves setting preferences among wishes and desires by deliberating their desirability and feasibility, and the postdecision (preaction) phase, which involves planning action implementation, are two distinct, consecutive phases of goal pursuit that differ in terms of the task that is to be solved by the individual. A person's psychological functioning in each of these phases is governed by different principles: the unique tasks associated with the different action phases lead to the activation of different cognitive procedures or mindsets.

A significant body of research has documented the distinct cognitive features of the mindsets typical of the predecision and postdecision action phases. In an early experiment, Heckhausen and Gollwitzer (1987) observed that deliberating (predecisional) participants demonstrated a heightened receptivity to available information (i.e., higher speed of processing of heeded but decision-irrelevant information) than planning (postdecisional) participants. Apparently, deliberating between potential action goals activates cognitive procedures (the deliberative mindset) that facilitate the task of the predecision phase, which is to set preferences. As undecided individuals do not know yet in which direction their decisions will finally take them, a heightened receptiveness to all kinds of information (open-mindedness) is appropriate and functional to task solution. On the other hand, planning out the implementation of a chosen goal activates cognitive procedures (the implemental mindset) that facilitate the task of the preaction phase (i.e., getting started on the chosen goal). Once a goal is set, successful goal implementation requires a more selective orientation to processing information (i.e., goal-irrelevant information is to be ignored) and closed-mindedness with respect to available information is called for. Recently, Fujita, Gollwitzer, and Oettingen (2007) built on these findings and showed that there are differences between the deliberative and implemental mindset in the open-minded processing of information, even if this information is presented incidentally.

Deliberative and implemental mindsets are also postulated to differentially affect the way in which desirability-related and feasibilityrelated information is dealt with. With respect to desirability-related information, deliberative mindset participants are found to analyze it impartially, whereas implemental mindset participants are observed to take a partial perspective in favor of the chosen goal (Beckmann \& Gollwitzer, 1987). In a study conducted by Taylor and Gollwitzer (1995, Study 3), predecisional participants deliberated their unresolved problems in an even handed manner by considering both the pros and cons, whereas postdecisional participants preferred to think about pros over cons, indicating a strong partiality to the chosen goal. Evidence for differences between the deliberative and implemental mindset in processing pros and cons is also provided by Harmon-Jones and Harmon-Jones (2002), who found that the implemental mindset increased postdecisional spreading of alternatives (i.e., the chosen option is evaluated more positively and the nonchosen option more negatively).

With respect to feasibility-related information, it has been observed that it is analyzed rather accurately in a deliberative mindset, whereas optimistic inferences that overestimate the actual feasibility of the chosen goal are characteristic of an implemental mindset. For instance, Gollwitzer and Kinney (1989) found that deliberating participants showed realistic judgments of control in a contingency-learning task, whereas planning participants' judgments of control were even more illusionary than those of the control participants. Taylor and Gollwitzer (1995) observed that for both controllable and uncontrollable risks, planning participants reported a higher invulnerability as compared to the average college student than deliberating participants did. Finally, when Gagne and Lydon (2001a) moved this biased inferences research to the real world by studying the issue of relationship predictions, they found that individuals in a deliberative mindset were more accurate in their forecasts of the survival of their romantic relationships than individuals in an implemental mindset.

Gollwitzer and Bayer (1999) pointed out that deliberative and implemental mindsets have been analyzed primarily in terms of their cognitive features. However, there are important behavioral consequences to be distinguished as well. For instance, Brand stätter and Frank (1997) report that implemental mindset participants persisted longer in solving a puzzle than deliberative mindset participants, and Armor and Taylor (2003) showed that implemental mindset participants exhibited comparatively higher task performance expectations, which in turn mediated better actual performance. Recent research by Henderson, de Liver, and Gollwitzer (2008) suggests that the beneficial effects of the implemental mindset on task performance might also be mediated by changes in respective attitude strength. Given the carryover properties of mindsets, Henderson and colleagues found that as people adopt an implemental mindset, they experience an increase in attitude strength towards objects even if these are unrelated to their current goal pursuit.

Apparently, the sum total of the cognitive orientation associated with the deliberative mindset (i.e., higher general open-mindedness and receptivity to available information, an impartial analysis of desirability-related information, and an accurate analysis of feasibilityrelated information) allows individuals to turn their wishes and desires into binding goals that are attractive and feasible. On the other hand, the sum total of the cognitive orientation associated with the implemental mindset (i.e., closed mindedness, cognitive tuning toward implementation-related information, partial analysis of desirability-related information, and illusionary analysis of feasibility-related information) allows individuals to effectively act on a chosen goal.

\section{Decisional status, deliberation, and goal commitment}

Deliberation and planning have in the past been conceptually attached to matching action phases, with deliberation being associated with the predecision action phase, and planning with the postdecision (preaction) phase (for reviews see Gollwitzer, 2011; Gollwitzer \& Bayer, 1999). However, from a pragmatic point of view people can be asked to adopt mismatching cognitive procedures. For example, even though researchers have generally examined the effects of deliberation in the context of the predecision action phase (i.e., asking predecisional research participants to deliberate the pros and cons of a decision to be made), deliberation can be triggered in postdecisional participants as well (i.e., asking postdecisional research participants to deliberate the pros and cons of a decision already made). Thus the question arises as to the consequences of assigning balanced deliberation in the pre- vs. postdecision action phase, and whether assigning such deliberation will have differential effects on goal commitment for pre- vs. postdecisional individuals.

\section{Pre- and postdecisional deliberation}

What happens when postdecisional individuals are forced to engage in balanced deliberation of pursuing or not pursuing their chosen goals? As balanced deliberation entails the consideration of not only the pros but also the cons of goal pursuit, it points to the potential negative outcomes of the already chosen goal, posing a threat to postdecisional individuals' existing goal commitment. Support for this contention comes from the escalation of commitment literature (e.g., Brockner, 1992), which has shown that negative feedback concerning the outcomes of goal pursuit is experienced as a threat by individuals, given that they have already personally chosen that course of goal pursuit. The need to justify prior goal choices has 
been found to lead individuals to reaffirm the correctness of their chosen goal by boosting their commitment and allocating even more resources to it (Brockner, 1992).

As discussed above, deliberating in the predecisional phase, where the task is to choose from among various wishes and desires, requires that feasibility-related information is analyzed objectively (and not in a self-serving manner) and desirability-related information in an impartial manner (and not in a one-sided manner; Gollwitzer, 1990). Once a goal decision has been made, however, the task is to promote the initiation of goal-directed behavior. Feasibility-related and desirability-related issues should no longer matter, and, if forced on the individual, they should be avoided by distorting the relevant information in support of the goal decision made: the person sees the feasibility of the chosen goal in an overly optimistic way (Gollwitzer \& Kinney, 1989) and views the desirability of the chosen goal in a partial manner (i.e., pros exceed cons; Taylor \& Gollwitzer, 1995). Given that the postdecisional mindset is associated with a cognitive orientation that facilitates the implementation of the chosen goal, postdecisional individuals have easy access to the cognitive procedures that promote holding on to a partial analysis, even when even-handed deliberation is requested. As a result, with postdecisional deliberation a defensive focus on the pros of goal pursuit should prevail and the commitment to the chosen goal should be strengthened.

\section{Defensive postdecisional deliberation}

Postdecisional individuals want to move forward on the task of implementing their chosen goal, and they have the proper mindset that facilitates this task (i.e., the relevant cognitive procedures are activated). Hence we expect that postdecisional individuals assigned with balanced deliberation would defend their existing goal commitment by distorting deliberation and focusing disproportionately on the pros of goal pursuit, a process we refer to as defensive postdecisional deliberation. In the current set of studies we provide evidence of defensive postdecisional deliberation by demonstrating both a disproportionate focus on the positive (as opposed to negative) outcomes and a focus on goal achievement-supportive information. Moreover, past research has explored self-defensiveness as an individual trait and has revealed stable differences between individuals high and low on this trait (e.g., Jacobson \& Ford, 1966; Mogg et al., 2000). As such, to provide converging evidence for our proposed defensive postdecisional deliberation process, we explore individual differences in self-defensiveness and show that our predicted effects of deliberation on goal commitment are stronger for individuals who are higher on this personality trait.

\section{Deliberation and goal commitment}

Following current conceptions of goal commitment we define this construct as the extent to which personal goals are associated with: a strong sense of determination, unwillingness to abandon or lower the original goal, willingness to invest effort, and effortful striving for goal implementation (e.g., Brunstein, 1993; Hollenbeck \& Klein, 1987; Kruglanski et al., 2002; Oettingen, Pak, \& Schnetter, 2001). Based on past research reviewed above on the distinct cognitive features of deliberative and implemental mindsets and the differential processing expected under pre- versus postdecisional deliberation, we argue that the consequences of pre- versus postdecisional deliberation on goal commitment should differ. Specifically, deliberation assigned to predecisional people should match their general cognitive orientation (i.e., deliberative mindset), thus promoting open-mindedness, impartiality with respect to desirability issues, and realistic assessment of feasibility issues, which in turn should make people even more undetermined and hesitant to commit to the goal in question. On the other hand, assigning deliberation to postdecisional people should mismatch their prevalent cognitive orientation (i.e., implemental mindset). Due to their quest for closed-mindedness, partiality towards the chosen alternative, and illusory optimism about its implementation, postdecisional people are cognitively well-prepared to defend their existing goal commitment against the doubt and uncertainty associated with forced balanced deliberation, by distorting the deliberation process and focusing on the pros of goal pursuit. As a consequence, strengthening of the existing goal commitment is to be expected.

\section{The present research}

In the current research we present four studies designed to systematically assess the effects of assigned pre- and postdecisional deliberation on participants' subsequent goal commitment. We employ several different operationalizations of goal commitment that reflect the different aspects of its definition, because there is no full consensus in the literature on how to measure goal commitment (Hollenbeck, Klein, O'Leary, \& Wright, 1989). Study 1 tests our hypothesis using a self-report measure of goal commitment that incorporates all four aspects of its definition (i.e., sense of determination, unwillingness to abandon or lower original goal, willingness to invest effort, effortful implementation striving). Study 2 replicates effects using the same measure and adds an indicator of goal commitment that reflects one's willingness to strive for goal implementation, following the idea that people who are not committed to a goal should not be willing to spend time planning its implementation (e.g., Gollwitzer, 1990; Oettingen \& Gollwitzer, 2001). Study 3 provides converging evidence by assessing persistence of goal pursuit, an indicator of goal commitment that reflects one's unwillingness to abandon a set goal and the willingness to invest effort (e.g. Gendolla \& Richter, 2010; Oettingen et al., 2001). Finally, Study 4 tests whether the commitment that deliberation produces is consequential by examining whether the effects of deliberation are substantial enough to stimulate goal adherence in real-life by enhancing the initiation of goal-directed behavior (Study 4).

As such, instead of relying only on self-report measures of goal commitment (in Studies 1 and 2), the cognitive and behavioral consequences of strong goal commitment are also assessed (in Studies 3 and 4); this approach is assumed to allow for a particularly valid assessment of goal commitment (Locke, Latham, \& Erez, 1988; Oettingen et al., 2009). Moreover, Studies 2, 3, and 4 examine the process underlying our proposed effects on goal commitment and show that defensive postdecisional deliberation - the focus on the positive outcomes of goal pursuit - is responsible for postdecisional deliberation's strengthening effects on goal commitment. Specifically, Study 2 shows that postdecisional individuals make overly optimistic estimates of the likelihood of the pros occurring, when forced to list an equal number of pros and cons of goal achievement, whereas Study 3 reveals that they generate more positive than negative outcomes when asked to engage in a spontaneous thought stream deliberation. Moreover, Study 4 provides evidence that the effects of defensive postdecisional deliberation are consequential and transfer to postdeliberation information processing by triggering a goal achievementsupportive information search.

Decision status is manipulated in different ways across the four studies: Studies 1 and 2 allow participants to pick their own goals that they are decided or undecided about, Study 3 allows decision status to develop naturally as the consequence of a manipulated decision environment, and Study 4 assigns deliberation over two goals, which participants (i.e., college students) are either decided or undecided about pursuing in everyday life.

\section{Study 1: deliberation effects on reported goal commitment}

The purpose of our first study is to establish the proposed phenomenon and assess the effect of assigned pre- and postdecisional deliberation on goal commitment. For this purpose, participants were asked to name either a goal they were decided to strive for or a potential goal they had not yet decided to strive for. Strength of goal 
commitment was assessed by self-report both prior to and after the assigned deliberation of the pros and cons of striving for the goal at hand. We predicted that deliberation would lower self-reported goal commitment for predecisional people, but that it would strengthen self-reported goal commitment for postdecisional people.

\section{Method}

\section{Participants}

Fifty-eight undergraduate students ( 30 women, 28 men) participated in this study in exchange for extra course credit. The age of participants in the sample ranged from 18 to 29 years. Participants received an email with a link that took them to an online survey containing the study materials.

\section{Design}

Participants were randomly assigned to one of two experimental conditions: predecisional condition (deliberate on a goal they were undecided about pursuing) versus postdecisional condition (deliberate on a goal they had decided to pursue). A measure of self-reported goal commitment was administered at two points in time, before and after assigned deliberation.

\section{Procedure and materials}

Participants were told that the study examines people's decisionmaking processes and that they would be asked to choose a persona goal and then take part in a decision-making exercise. They were instructed to respond to the study when no other people were around, to minimize distractions. In the predecisional condition, participants were asked to choose a personal goal, which they had not yet decided to strive for. Instructions were as follows: "In this study your task will be to choose an unresolved personal goal and weigh the pros and cons of pursuing or not pursuing this personal goal. The goal should be something of present concern that you have not yet decided to strive for, and it should be unresolved, i.e., you should not have yet reached a decision on the matter. This unresolved goal should be important and take the form of "Should I do X or not?" (e.g., Should I switch my major or not?)."

In the postdecisional condition, participants were asked to choose a personal goal they had already decided to strive for: "In this study your task will be to choose a personal goal you have already decided to strive for and weigh the pros and cons of pursuing or not pursuing this personal goal. You should choose a personal goal that you plan to accomplish within the following three months. Please choose a goal that you really intend to accomplish in the near future (e.g., switch my major)." After participants stated their personal goal they indicated the importance of their chosen personal goal, measured on a 7-point scale ranging from $1=$ not important to $7=$ very important. ${ }^{1}$

Manipulation check. After participants named their personal goal they were directed to the next page where they responded to a decision status manipulation check to ensure that they had deliberated on goals appropriate to their experimental condition. Both groups completed two critical items designed to determine whether postdecisional participants had indeed chosen a goal which they had decided to strive for, whereas predecisional participants had chosen a goal which they had not yet decided to strive for. The first critical item asked them how close they were to making a decision whether to pursue their chosen personal goal (ranging from $1=$ far from making $a$ decision to 13 = past having made a decision; Gagne \& Lydon, 2001b; Gollwitzer \& Kinney, 1989); the second critical item determined how close

\footnotetext{
${ }^{1}$ In Studies 1 and 2, where participants could pick personal goals to deliberate on we measured goal importance to ensure that participants picked goals with a similar level of importance. Goal importance neither differed across experimental conditions, nor modified the observed results, so it is not discussed further.
}

participants were to achieving their goal (ranging from $1=I$ am not yet in the act of making a decision to pursue my potential personal goal to $5=I$ have achieved my chosen personal goal; Gagne \& Lydon, 2001b).

Goal commitment: baseline measure. After pre- and postdecisional participants had named their chosen goals and answered the respective manipulation checks, we measured their baseline commitment to the goal. We used a five-item short form of the Hollenbeck, Williams, and Klein's (1989) Goal Commitment Scale $(\alpha=.79$; DeShon \& Landis, 1997), which asks participants to indicate their agreement, on a 7-point scale ranging from $1=$ strongly disagree to $7=$ strongly agree, with the following five statements: "Quite frankly I don't care if I achieve this goal or not," (reverse scored); "I am strongly committed to pursuing this goal"; "It wouldn't take much to make me abandon this goal," (reverse scored); "I think this goal is a good goal to shoot for"; and "I am willing to put in a great deal of effort to achieve this goal."

Deliberation instructions. Next, participants had to proceed to the deliberation exercise. We used a procedure consistent with past research (e.g., Gollwitzer \& Kinney, 1989). We first provided participants with a written example of how the exercise should be completed, ostensibly done by a former participant. The example involved deliberating on the goal of going on a vacation during spring break. Participants were asked to study the example carefully. The next page presented participants with a blank exercise form so that they could proceed and apply the exercise to their own personal goal. They were requested to first list the immediate and delayed positive and negative consequences of pursuing their personal goal. Finally, participants listed the immediate and delayed positive and negative consequences of not pursuing their personal goal.

Goal commitment: post-deliberation measure. After participants had engaged in deliberation the same goal commitment scale described above $(\alpha=.87)$ was applied a second time.

\section{Results and discussion}

\section{Content of goals named}

Adopting a coding system used in prior research (Gollwitzer, Heckhausen, \& Steller, 1990; Henderson et al., 2008), we classified the personal goals participants named into three categories and found that $58 \%$ of participants' goals dealt with career-related issues (e.g. find a part-time job), 34\% dealt with lifestyle-related issues (e.g., get a gym membership), and $8 \%$ dealt with interpersonal issues (e.g., break up with my partner).

\section{Manipulation check}

Participants in the postdecisional condition indicated they were significantly closer to making a decision to pursue their chosen personal goal $(M=10.60, S D=2.96)$ than participants in the predecisional condition $(M=7.20, S D=2.50), t(56)=4.70, p<.001, d=1.24$, and significantly closer to achieving their personal goal $(M=3.60, S D=.72)$ compared to predecisional participants $(M=2.50, S D=.83), t(56)=$ $5.40, p<.001, d=1.42$. Thus the manipulation check confirmed that participants in the postdecisional condition were more decided about their goals than participants in the predecisional condition.

\section{Hypothesis testing}

To test our hypothesis that assigned deliberation strengthens goal commitment for postdecisional people (i.e., who were already decided on striving for the goal they deliberated), but weakens goal commitment for predecisional people (i.e., who deliberated a goal they are undecided about), we ran a 2 within (Goal Commitment: predeliberation vs. post-deliberation) $\times 2$ between (Decisional Status: predecisional vs. postdecisional) factorial ANOVA on participants' goal 
commitment. ${ }^{2}$ Results revealed a significant main effect of the between-subjects decisional status factor, $F(1,56)=14.57, p<.001$. The within-subject factor of goal commitment produced a significant interaction with the decisional status between-subjects factor, $F(1,56)=15.03, p<.001$.

Follow-up contrasts compared the change in goal commitment within the pre- and postdecisional experimental groups and revealed that goal commitment significantly increased as a result of deliberation for the postdecisional group $\left(M_{\text {pre-deliberation }}=6.10, S D=1.00\right.$; $\left.M_{\text {post-deliberation }}=6.60, S D=.48\right), t(29)=2.71, p<.01, d=1.07$, but significantly decreased as a result of deliberation for the predecisional group $\left(M_{\text {pre-deliberation }}=5.70, S D=.85 ; M_{\text {post-deliberation }}=5.20, S D=\right.$ 1.60), $t(27)=2.75, p<.01, d=1.00$ (see Fig. 1). These results suggest that deliberation serves to strengthen goal commitment for postdecisional individuals, but actually weakens goal commitment for predecisional ones. Moreover, postdecisional participants reported a significantly stronger baseline goal commitment $(M=6.10, S D=$ $1.00)$ as compared to predecisional ones $(M=5.70, S D=.85), t(56)=$ $1.80, p<.07, d=.60$, and postdecisional participants who were asked to deliberate a goal they had already decided to strive for, reported significantly stronger goal commitment after deliberation $(M=6.60$, $S D=.48$ ), as compared to predecisional people who were asked to deliberate a goal they were still undecided about $(M=5.20, S D=1.60)$, $t(56)=5.40, p<.001, d=1.64$ (see Fig. 1)

As expected, our results confirmed that postdecisional deliberation (i.e., deliberating on a goal one has decided to strive for) leads to a significantly stronger goal commitment, whereas predecisional deliberation (i.e., deliberating on a goal which one has not decided to strive for) weakens goal commitment. In other words, with respect to the consequences of deliberation on commitment it matters whether deliberation is predecisional or postdecisional. Goal commitment was assessed in Study 1 by asking participants to report solely on the strength of their intentions to act on the goal (i.e., using items such as "I'm willing to put in a great deal of effort to achieve this goal"). But would these observed differences in strength of intention be consequential? Accordingly, in Study 2 we assessed commitment by asking participants to report on an important cognitive consequence: intensive planning of goal implementation. Even though commitment is assessed via this different indicator in Study 2, we hypothesized that the effects of postdecisional deliberation as observed in Study 1 should prevail again.

\section{Study 2: deliberation effects on subsequent planning activity}

People's strength of goal commitment can be inferred from their willingness to plan the implementation of a given goal (e.g., Gollwitzer, 1990; Oettingen \& Gollwitzer, 2001). Even though planning is a distinct construct, it has been used as a valid indicator of goal commitment in past literature (e.g., Oettingen et al., 2001), under the assumption that people who are not committed to a goal should not be willing to spend any time planning how to achieve that goal. Good planning is associated with an increased focus on the means and actions needed to implement a goal and we operationalized and measured it in terms of two aspects of clarity of means - the extent to which one is clear on (a) what means need to be used to be successful with a personal goal (Emmons, 1986), and on (b) when, where, and how these means need to be used for the goal to be achieved (Gollwitzer \& Brandstätter, 1997).

The aim of Study 2 is twofold. First, we aim to show that postdecisional individuals respond to assigned deliberation by intensified planning, whereas predecisional people become less concerned with planning as a result of assigned deliberation. Note that we are no

\footnotetext{
${ }^{2}$ In both Studies 1 and 2 we also analyzed the data by employing the moderation testing procedure recommended by Judd, Kenny, and McClelland (2001) and regressed the difference in commitment as a result of deliberation on experimental condition. In both studies results were consistent and highly significant.
}

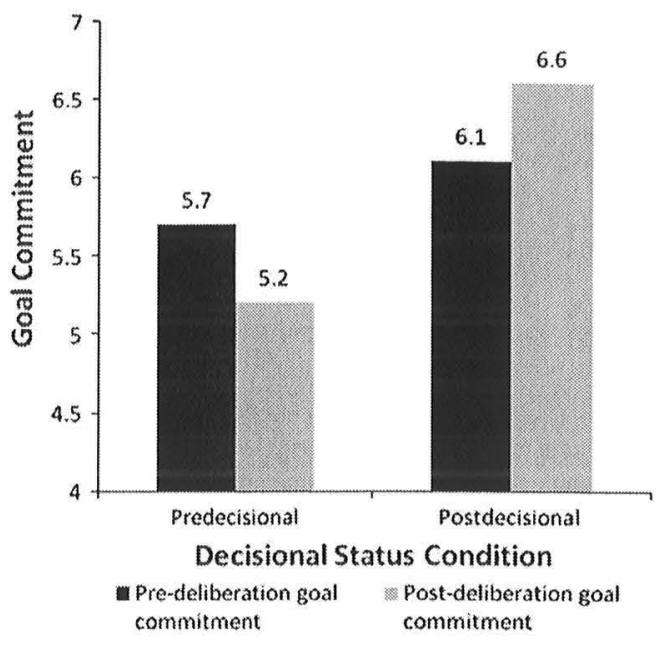

Fig. 1. Study 1: pre- and post-deliberation self-reported goal commitment for pre- and postdecisional individuals. Commitment was measured on a 7-point scale.

longer only asking participants about their felt strength of goal commitment. In addition, we measure a cognitive activity (i.e., planning intensity) that is indicative of possessing a strong goal commitment (Oettingen \& Gollwitzer, 2001; Oettingen et al., 2001). Second, we explore the process underlying these effects by testing whether forcing postdecisional individuals to list an equal number of pros and cons leads them to focus defensively on the pros of goal pursuit by overestimating their likelihood of occurring.

Method

\section{Participants}

One hundred and eighteen students (59 women, 59 men) were recruited for this study and received extra course credit for participation. The ages of participants in the sample ranged from 17 to 34 years. Participants received an email with a link that took them to an online survey containing the study materials.

\section{Design}

Participants were randomly assigned to one of two experimental conditions: predecisional condition (deliberate on a goal they were undecided about pursuing) versus postdecisional condition (deliberate on a goal they had decided to pursue). Measures of self-reported goal commitment and planning intensity were administered at two points in time, before and after assigned deliberation.

\section{Procedure and materials}

Participants were first told that the study examined people's decision-making processes and that they would be asked to choose a personal goal and then take part in a decision-making exercise. Participants in the predecisional condition were then asked to choose a personal goal which they have not yet decided to strive for and participants in the postdecisional condition were asked to choose a personal goal which they had decided to strive for, using the same instructions described in Study 1. After participants stated their personal goal they indicated the difficulty of the chosen goal by reporting on the perceived amount of challenge, effort, and persistence and tenacity that this goal would evoke in the average person who has a similar level of education and experience as them (9-point semantic differential scale). ${ }^{3}$ Next, in both conditions participants received deliberation

\footnotetext{
${ }^{3}$ Goal difficulty was measured to ensure that participants picked goals with a similar level of difficulty. Goal difficulty neither differed across experimental conditions, nor modified the observed results, so it is not discussed further.
} 
instructions asking them to list the positive and negative consequences of pursuing or not pursuing their personal goal and estimate the likelihood (expressed in a percentage) that each of these consequences would actually occur (Gollwitzer \& Kinney, 1989).

Manipulation check. We used the same two critical items as in Study 1 to determine whether postdecisional participants had indeed chosen a goal which they were decided to strive for, whereas predecisional participants had chosen a goal which they were not yet decided to strive for (Gagne \& Lydon, 2001b; Gollwitzer \& Kinney, 1989).

Goal commitment: baseline measure. After participants named their chosen goal we measured their baseline commitment to the goal using the same five-item goal commitment scale used in Study 1 $(\alpha=.73$; DeShon \& Landis, 1997).

Goal commitment: post-deliberation measure. Post-deliberation goal commitment was measured as a dependent variable in order to replicate the Study 1 results. The same goal commitment scale described above was used $(\alpha=.78)$.

Planning intensity: baseline measure. The "what" aspect of planning intensity was assessed using a measure proposed by Emmons (1986), which consists of one item asking participants "How clear an idea do you have of what you need to do to be successful with this goal?" The question was answered on a 9-point scale ranging from $1=$ not clear at all to $9=$ very clear. The "when" and "where" aspects of planning intensity were assessed by asking participants whether they had formed implementation intentions on when and where to initiate goal-directed actions. Following Gollwitzer and Brandstätter (1997), we told participants:

"In order to achieve their goals people execute behaviors that can be described along three dimensions. One refers to the point in time, the second to the place, and the third to the type of action that is linked to the situational context specified by time and place. Please indicate whether you have by now committed yourself to certain specific goal-directed actions in the sense of "When I encounter the situational context $y$, then I will perform behavior $z$ !".

Once participants had indicated the formation of implementation intentions by a yes or no answer, we assessed the number of implementation intentions that each participant had formed. For this purpose, participants were asked to describe the chosen actions and the respective situational contexts in their own words (e.g., "When I encounter junk food, then I will find something healthier to eat instead").

To simplify the exposition, the two aspects of planning intensity, how clear participants are on what they need to do to attain the goal and whether they report that they have formed implementation intentions $\left(\mathrm{r}_{\text {pre-deliberation }}=.55, p<.01\right)$, were first standardized using $z$-scores (due to their different measurement scales) and then averaged to form a composite planning intensity score, which is used in further analysis.

Planning intensity: post-deliberation measure. Participants' planning intensity after deliberation was assessed using the same method described above (i.e., combining the two standardized aspects of planning intensity in a planning intensity score, $\mathrm{r}_{\text {post-deliberation }}=.63, p<.01$ ).

Deliberation instructions. The same deliberation instructions as in Study 1 were used. In addition, in this study participants were asked to estimate the likelihood (expressed in a percentage) that each of their listed consequences would actually occur.
Defensive processing. To test our predictions of the process underlying the differential effects of pre- and postdecisional deliberation on goal commitment we examined the content of participants' deliberation for evidence of a defensive focus on the pros of goal pursuit. Specifically, two scores were calculated for each participant: 1) average likelihood of the pros of goal pursuit (i.e., mean of estimated likelihood of the positive consequences of pursuing the goal and negative consequences of not pursuing it), and 2) average likelihood of the cons of goal pursuit (i.e., mean of estimated likelihood of the negative consequences of pursuing the goal and the positive consequences of not pursuing it). To provide evidence of defensive postdecisional deliberation, we expected to find that, as compared to predecisional participants, postdecisional ones tend to overestimate the likelihood of the pros of goal pursuit.

Results

\section{Content of named goals}

Adopting the coding scheme used in Study 1, we coded the personal goals people chose to deliberate on and found that $62 \%$ of participants' goals dealt with career-related issues (e.g., get a summer internship), $32 \%$ dealt with lifestyle-related issues (e.g., quit smoking), and 6\% dealt with interpersonal issues (e.g., confess romantic feelings to a friend).

\section{Manipulation check}

Participants in the postdecisional condition indicated they were significantly closer to making a decision whether to pursue their chosen personal project $(M=11.20, S D=2.43)$ than participants in the predecisional condition $(M=8.30, S D=3.29), t(116)=5.40, p<.001$, $d=1.04$, and closer to achieving their chosen personal project $(M=3.50, S D=.78)$ compared to predecisional participants $(\mathrm{M}=2.30, S D=1.06), t(116)=6.90, p<.001, d=1.30$.

\section{Hypotheses testing}

Goal commitment scale. To replicate Study 1 results, we first tested our hypothesis about the differential effects of deliberation on participants' scores on the goal commitment scale. For this purpose we ran a onefactor, repeated-measures ANOVA on participants' pre- and postdeliberation goal commitment. Results confirmed our findings from Study 1 revealing a significant main effect of the between-subjects decisional status factor, $F(1,116)=14.62, p<.001$, and a significant interaction between the within-subjects factor of goal commitment and the between-subjects decisional status factor, $F(1,116)=12.19$, $p<.001$.

Follow-up contrasts compared the change in goal commitment within the pre- and postdecisional experimental groups and confirmed findings from Study 1 - goal commitment significantly increased as a result of deliberation for the postdecisional group $\left(M_{\text {pre-deliberation }}=7.60\right.$, $\left.S D=.99 ; M_{\text {post-deliberation }}=7.90, S D=.91\right), t(60)=3.38, p<.001, d=.90$, but significantly decreased as a result of deliberation for the predecisional group $\left(M_{\text {pre-deliberation }}=7.10, S D=1.39 ; M_{\text {post-deliberation }}=6.80\right.$, $S D=1.52), t(56)=2.23, p<.05, d=.60$ (see Fig. 2a). These results confirm our previous findings that deliberation serves to further strengthen goal commitment for postdecisional individuals, but weakens goal commitment for predecisional ones. Furthermore, postdecisional participants again reported a significantly stronger baseline goal commitment $(M=7.60, S D=.99)$ as compared to predecisional ones $(M=7.10, S D=1.39), t(116)=2.40, p<.01, d=.60$; as well as a stronger goal commitment after deliberation $(M=7.90, S D=.91)$ as compared to predecisional participants $(M=6.80, S D=1.52), t(116)=4.32, p<.001$, $d=.90$ (see Fig. 2a).

Planning intensity. We first calculated the correlation between our two dependent variables - goal commitment scale and planning intensity $\left(r_{\text {predeliberation }}=.20, p<.05 ; r_{\text {postdeliberation }}=.40, p<.01\right)$. We then ran a 2 


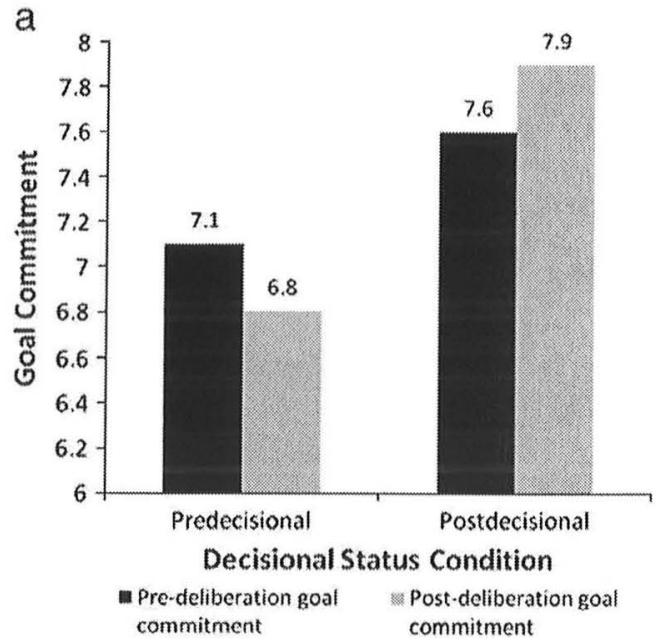

b

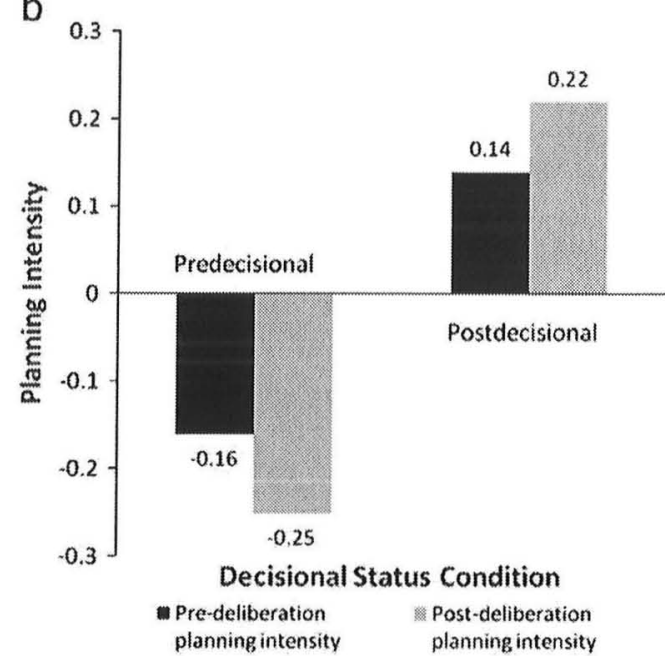

Fig. 2. $a$. Study 2: pre and post-deliberation self-reported goal commitment for pre- and postdecisional individuals. Commitment was measured on a 9-point scale. $b$. Study 2 : Pre- and post-deliberation planning intensity for pre- and postdecisional individuals. Planning intensity was measured by a standardized ( $z$ score) composite planning intensity score.

within (Planning intensity: pre-deliberation vs. post-deliberation) $\times 2$ between (Decisional Status: predecisional vs. postdecisional) factorial ANOVA on participants' planning intensity. Results revealed a significant main effect of the between-subjects decisional status factor, $F(1,116)=$ $9.31, p<.001$, and a significant interaction between the within-subject goal commitment factor and the between-subjects decisional status factor, $F(1,116)=3.69, p<.05$.

Follow-up contrasts compared the change in planning intensity within the pre- and postdecisional experimental groups and revealed that planning intensity significantly increased as a result of deliberation for the postdecisional group $\left(M_{\text {pre-deliberation }}=.14, S D=.68 ; M_{\text {post-deliberation }}=\right.$ $.22, S D=.63), t(60)=2.17, p<.05, d=.57$, but decreased, albeit not significantly, as a result of deliberation for the predecisional group $\left(M_{\text {pre-deliberation }}=-.16, S D=.80 ; M_{\text {post-deliberation }}=-.25\right.$, $S D=.81$ ) $, t(56)=1.30, p<.2, d=.30$ (see Fig. 2b), suggesting that assigned deliberation serves to intensify postdecisional individuals' planning activity. No such intensification of planning is found for predecisional individuals; rather, the already weak planning intensity is weakened even further, albeit not significantly. Moreover, postdecisional participants reported significantly stronger baseline planning intensity $(M=.14, S D=.68)$ as compared to predecisional ones $(M=-.16$, $S D=.80), t(116)=2.10, \mathrm{p}<.05, d=.50$; and this difference became even stronger after deliberation $(M=.22, S D=.63$ vs. $M=-.25$, $S D=81$ ) $, t(116)=2.85, p<.01, d=.67$ (see Fig. 2b). These results support our prediction that assigned deliberation leads to heightened planning activity for participants who are in the postdecision, as compared to the predecision action phase.

Defensive processing. To test for evidence of defensive postdecisional deliberation we compared participants' estimated likelihood that the pros and cons of goal pursuit they listed will actually occur. Results revealed that, as expected, on average postdecisional participants estimated the pros of goal pursuit as significantly more likely to occur $(M=.80, S D=.34)$, as compared to predecisional participants $(M=.64, S D=.24), t(110)=2.37, p<.01, d=.54$. On the other hand, there was no difference in the estimated likelihood of the cons of goal pursuit $\left(M_{\text {predecisional }}=.65, S D=.23 ; M_{\text {postdecisional }}=.66, S D=\right.$ .16), $t(107)=.75, p<.50, d=.05$ (see Table 1$){ }^{4}$ These results provide evidence for our hypothesis of defensive postdecisional deliberation.

Mediation testing. Finally, we checked whether the likelihood of the consequences participants generated mediates the effects of pre-versus postdecisional deliberation on goal commitment. To test for mediation, we followed the procedure recommended by Baron and Kenney (1986). Results revealed that participants' estimated likelihood of the pros of goal pursuit is a mediator of the effects of pre- versus postdecisional deliberation on goal commitment. In Step 1, a regression indicated that experimental condition is a significant predictor of the average likelihood of the pros of goal pursuit, $F(1,110)=27.16, p<.001$; $b=.24, p<.001$. In Step 2, a regression confirmed that the estimated likelihood of the pros is a significant predictor of post-deliberation goal commitment, $F(1,110)=24.79, p<.001 ; b=2.13, p<.001$. In Step 3, experimental condition was confirmed to be a significant predictor of participants' goal commitment, $F(1,116)=16.64, p<.001 ; b=0.96$, $p<.001$. Finally, it was revealed that the effect of experimental condition on goal commitment is partially mediated by participants' estimation of the likelihood of pros, $F(2,109)=14.84, p<.001, b_{\text {condition }}=0.52, p<.05$, $b_{\text {pros likelihood }}=1.70, p<.001$, Sobel $z=3.15, p<.001$. These results suggest that the overweighing of the pros of pursuing the chosen goal contributes to the strengthening effects of postdecisional deliberation on goal commitment.

\section{Discussion}

Results from Study 2 provided further support for our contention that pre-versus postdecisional deliberation has opposing effects on goal commitment. First, we replicated our findings from Study 1 and confirmed that deliberation increases participants' scores on the goa commitment scale (i.e., indicating strength of intention to meet the goal) for postdecisional individuals, but decreases it for predecisional ones. Second, our predicted effects also emerged when using planning intensity as an indicator of goal commitment. Specifically, we found that deliberation affects not only individuals' scores on the goal commitment scale, but also their planning activity: postdecisional individuals dealt with deliberation by planning even more, whereas predecisional individuals remained less concerned with planning when asked to engage in deliberation. Since planning intensity is an important indicator of strong goal commitment as it allows for effective goal striving (Oettingen \& Gollwitzer, 2001; Oettingen et al., 2001), these results provide converging support for our proposed effects of deliberation on goal commitment. It should be noted that even though deliberation produced a significant decline in goal commitment scores in predecisional participants, the parallel decline in planning intensity as a result of deliberation did not reach significance for predecisional individuals. This non-significant result is likely due to a floor effect - as

\footnotetext{
${ }^{4}$ Degrees of freedom vary for the likelihood analyses because of missing values, as not all participants provided likelihood estimates for all of their listed consequences.
} 
Table 1

Study 2: estimated likelihood of listed consequences.

\begin{tabular}{|c|c|c|}
\hline & Predecisional condition & Postdecisional condition \\
\hline & mean $(S D)$ & mean $(\mathrm{SD})$ \\
\hline $\begin{array}{l}\text { Likelihood of pros of } \\
\text { goal pursuit }\end{array}$ & $.64(.24)^{*}$ & $.80(.34)^{*}$ \\
\hline $\begin{array}{l}\text { Likelihood of cons of } \\
\text { goal pursuit }\end{array}$ & $.65(.23)$ & $.66(.16)$ \\
\hline
\end{tabular}

predecisional individuals' planning intensity was very weak to begin with, there was hardly room for further decline caused by deliberation.

Findings from Study 2 also supported our defensive postdecisional deliberation hypotheses by providing evidence that postdecisional individuals who are forced to list an equal number of pros and cons of goal pursuit defensively overestimate the likelihood of the pros of pursuing their chosen goal. It seems that even when requested to list an equal number of pros and cons, postdecisional participants distort the assigned balanced deliberation by expressing overly optimistic estimates of the pros' likelihood. Our mediation analysis further showed that this overestimation of the likelihood of the pros is partially responsible for the obtained effects on commitment.

In Study 3 we build on these findings and provide further evidence for this hypothesis by employing a less restrictive deliberation procedure assessing spontaneous thoughts (e.g., Heckhausen \& Gollwitzer, 1987), which allows us to tap into pre- and postdecisional participants' spontaneous generation of positive and negative consequences. In the previous two studies commitment was assessed via self-report (on the strength of the intention to meet the goal in Study 1 , and on the intensity of planning out one's goal striving in Study 2). This assumes that people have insight into the determinants and concomitants of their goal commitments, when in fact they often do not (Oettingen et al., 2009). To address this concern, in the following two studies we employ indicators of goal commitment that are not biased by individual insight. Specifically, we show that the uncovered effects of deliberation on goal commitment affect a person's actual goal striving. As commitment represents the extent to which a person feels compelled to act in the service of attaining a goal, behavioral indicators of goal striving are considered to be particularly valid measures of commitment (Klein, Becker, \& Meyer, 2009; Locke et al., 1988) and have been widely employed as such (e.g. Oettingen et al., 2009). Hence, in the following two studies we extend our analyses to two aspects of goal striving - persistence in goal striving (Study 3) and real-life behavior (Study 4).

\section{Study 3: deliberation effects on goal persistence}

In this study we build on previous findings in three ways: first, we employ a different manipulation of decision status - unlike in Studies 1 and 2, where we asked people to choose a personal goal they had either decided or not decided to strive for, here we allowed decision status to develop naturally as the consequence of a manipulated decision environment. Second, we look at participants' persistence of goal pursuit - an important behavioral indicator of goal commitment (Oettingen et al., 2001). In this study we do not rely on self-reports, but assess effortful goal striving via participants' persistence in pursuing a goal. Third, we use a deliberation procedure that assesses spontaneous thoughts (Heckhausen \& Gollwitzer, 1987); it taps into participants' spontaneous consequences generation, allowing us to provide more evidence for our defensive postdecisional deliberation hypothesis Finally, in our Study 3 we examine a boundary condition for the effect of deliberation on goal commitment. According to our hypothesis, deliberation strengthens goal commitment in postdecisional individuals via emphasizing the pros of the chosen goal to defend the existing goal commitment against the threat of assigned balanced deliberation. If this reasoning is correct, then the extent to which people differ in selfdefensiveness as a personal trait should also influence the impact of deliberation on goal commitment, so that individuals who are personally more defensive should respond to postdecisional deliberation by strengthening their goal commitment to a higher extent, as compared to less defensive individuals.

Method

\section{Participants}

Eighty seven adults ( 26 women, 61 men) from a nationwide panel of respondents were paid to participate in an online experiment. Participants' age ranged from 18 to 64 years. They received an email with a link that took them to an online survey containing the study materials.

\section{Design}

Participants were randomly assigned to one of two experimental conditions: predecisional and postdecisional condition. Deliberation was assigned under the guise of a thought sampling exercise, after which participants' persistent effort towards solving anagrams was measured. At the end of the experiment, after some unrelated filler measures, participants' responses to a measure of individual differences in self-defensiveness were assessed and demographic information was collected.

\section{Procedure and materials}

Participants were told that this is a study designed to measure their concentration potential. They were informed that there were two different computer tasks designed for this purpose, one based on "semantic (i.e., meaning-based) stimuli" and the other based on "spelling (i.e., writing-based) stimuli," and they could demonstrate their true potential only if they picked the task that was "right" for them. Unbeknownst to participants, the two "different" computer tasks were the same task. Participants were presented with the illusion of two tasks to create an experimental situation in which they have to make a goal decision (for similar manipulations of decision status, see Fujita et al., 2007; Gollwitzer \& Kinney, 1989, Study 1; Heckhausen \& Gollwitzer, 1987).

Decision status manipulations. Following the procedure used by Fujita et al. (2007), participants in the undecided status condition were instructed to suspend any preconceptions about whether they preferred semantic or spelling stimuli. They were told that the best decision could be made only after they had tried each type of task. While trying out the tasks, participants were instructed to consider carefully whether it was the right task for them, but not to make up their minds until they had performed both. They were then given a choice which task they wanted to try first. The task they subsequently performed was the same task performed in the decided experimental condition. To prevent a premature goal decision made on the basis of the choice of which task to try first, after participants indicated their choice, they were reminded to ask themselves continually whether they felt that the task they were performing would most accurately demonstrate their concentration potential. When participants were finished, they were informed that they would not have to perform the other task nor make a final decision as to which task they wanted to perform. They then continued to the next part of the experiment.

Participants in the decided status experimental condition were asked to think about the activities they commonly engage in, and asked whether they would feel more comfortable with semantic or spelling tasks. They were urged to think deeply about this decision and to avoid impulsive choices, as they would not be able to reverse their decision. Once participants had made their decision and indicated their task choice, they performed the appropriate task (which again, was the same task regardless of decision). In this way, 
participants in the decided status condition performed the task for which they had made a goal decision.

Deliberation instructions. Participants in both experimental conditions were told that before performing the concentration task they would be asked to participate in a thought sampling exercise, where they will have to think about and report the pros and cons of performing the concentration task they are pretesting and evaluating (have chosen to perform). After participants indicated their task preference by clicking on a button at the bottom of the screen, they were directed to the thought sampling exercise on the next screen, where they were presented with a self-report sheet. This self-report sheet was designed to elicit the consequences that came to participants' minds from the time they were told they would have to choose between two types of concentration tasks (they chose between the two types of concentration tasks) until the present time. The format was as follows: subjects first reported the most recent consequence of performing the task they were pretesting first (their chosen task) that came to their minds, then the second most recent consequence, thereafter the first consequence that came to their mind, and finally, all the other consequences that came to their mind in between.

Dependent variable. Once they completed the thought sampling exercise, participants were given the Mental Concentration Task and instructions on how to complete it. In both experimental conditions the task was the same and consisted of solving a series of 20 very difficult anagrams. Participants were told to work on as many anagrams as they wanted, until they decided to give up. Our dependent variable thus was persistent effort directed at the task of solving anagrams (for a recent review of measures of effort see e.g., Gendolla \& Richter, 2010).

Self-defensiveness. Individuals high in self-defensiveness tend to evade endorsement of socially unsanctioned thoughts and behaviors, and relevant to the present research - avoid recognition of painful psychological material (Harrigan, Harrigan, Sale, \& Rosenthal, 1996). We used Crowne and Marlowe's (1960) Social Desirability Scale (SDS) to assess self-defensiveness as more than four decades of research have established the utility of the SDS as a measure of individual levels of self-defensiveness (e.g., Esterling, Antoni, Kumar, \& Schneiderman, 1993; Evans, 1979; Harrigan et al., 1996; Jacobson \& Ford, 1966; Mogg et al., 2000). The SDS was originally designed to assess individual tendencies to respond in a culturally sanctioned and desirable manner to gain approval from others (Crowne \& Marlowe, 1960). In their original scale development effort, Crowne and Marlowe (1960) noted high positive correlations between the SDS and measures of defensiveness. Subsequent research further confirmed that there is a strong relationship between SDS scores and individual self-defensive tendencies (e.g., Evans, 1979; Harrigan et al., 1996; McCabe, 1989). A short 13-item version of the scale developed by Reynolds (1982) was employed $(\alpha=.74)$ at the end of the experiment after some unrelated filler measures. Responses ranged from $1=$ strongly disagree to $7=$ strongly agree (eight items were reverse coded).

\section{Results and discussion}

\section{Goal persistence}

We first ran the Shapiro - Wilk test for normality, which suggested that the time latency measure - the time participants spent solving anagrams - is not normally distributed, $\mathrm{W}=.36, p<.01$. Therefore, we conducted a non-parametric Wilcoxon-Mann-Whitney test, which confirmed that goal persistence is significantly different across the two experimental conditions, $z=2.36, p<.01$. Additionally, we conducted a log transformation on the goal persistence dependent variable, which normalized the distribution, $\mathrm{W}=.99, p<.80$, and ran a one-factor ANOVA on the log transformed variable, with decisional status experimental condition as the independent variable, and whether or not participants have solved anagrams before and whether or not English is their native language as controls. Results again revealed a significant main effect of decisional status, $F(3,83)=$ $8.88, p<.01$. None of the control variables had a significant effect on goal persistence. Follow-up contrasts revealed that postdecisional deliberation $(M=911.27 \mathrm{~s}, S D=1433.78)$ led to significantly more persistence than did predecisional deliberation $(M=314.18 \mathrm{~s}$, $S D=523.33), t(85)=1.96, p<.05, d=.55$. These results provide converging support for our thesis and suggest that assigned deliberation leads to greater goal persistence on the part of postdecisional individuals, as compared to predecisional ones.

It should be noted that in order for us to vary decision status, we had predecisional participants expect to perform two different concentration tasks, whereas we had postdecision participants expect to only perform one task (i.e., the task they had already chosen). One might want to argue therefore that predecisional participants spent less time on solving anagrams in anticipation of the next task they thought they would also be performing. However, this alternative explanation does not seem viable as anticipated challenges commonly lead to an increase in energization (e.g., Wright, 2008) that in turn facilitates effort expenditure and persistence (e.g., Oettingen et al., 2001). In other words, the expected pattern of results evinced even though the named aspect of our manipulation of decisional status militated against it.

\section{Defensive processing}

Two independent judges, unaware of the study hypotheses, coded participants' listed thoughts as pros of goal pursuit (e.g., "Will have fun performing the task"), cons of goal pursuit (e.g., "Will embarrass myself if I choose wrong"), or non-consequences (e.g., "I am gearing up to remember spelling rules"). Inter-rater agreement was $87 \%$ for pros, $90 \%$ for cons, and $92 \%$ for non-consequences, with disagreements resolved through discussion. Table 2 presents descriptive statistics and mean contrasts for participants' listed consequences. ${ }^{5}$

To simplify the exposition, we calculated a relative pro-focus index by taking the difference between the number of pros and number of cons participants listed, and ran an ANOVA on this index with decision status as the independent variable. Results revealed that postdecisional individuals had a significantly higher relative pro focus index $(M=.42, S D=1.43)$ than predecisional individuals $(M=-.74, S D=1.70), t(85)=2.94$ $p<.01, d=.67$, providing evidence of the defensive focus on positive outcomes on the part of postdecisional individuals. Additionally, we found that $43 \%$ of postdecisional individuals listed a pro as the first consequence that came to their minds as compared to only $8 \%$ of predecisional individuals who did so, $\chi^{2}=11.57, p<.001$. Consistently significant results were obtained when number of pros of goal pursuit was used in the analysis instead of the relative pro-focus index.

\section{Mediation testing}

Next we checked whether the relative pro-focus index mediates the effects of pre- versus postdecisional deliberation on goal pursuit persistence. To test for mediation, we followed the procedure recommended by Baron and Kenney (1986). First, we confirmed that decision status condition is a significant predictor of goal persistence (log transformed), $F(1,85)=8.99, p<.01 ; b=-.98, p<.01$. Next, a regression confirmed that decision status condition is a significant predictor of the relative pro-focus index, $F(1,85)=8.66, p<.01 ; b=$ $-1.05, p<.01$. In the next step, a regression confirmed that the relative pro-focus index is a significant predictor of goal persistence (log

\footnotetext{
${ }^{5}$ It is notable that participants listed a greater number of non-consequences as compared to the number of either pros or cons they listed. This is likely due to the nature of the stream of spontaneous thought deliberation procedure we used, which is conducive to listing all of the various thoughts participants generated (e.g. Heckhausen \& Gollwitzer, 1987). However, the number of non-consequences was smaller than the combined number of pros and cons participants listed (see Table 2).
} 
Table 2

Study 3: number of listed consequences.

\begin{tabular}{lccc}
\hline & $\begin{array}{l}\text { Predecisional } \\
\text { condition }\end{array}$ & & $\begin{array}{l}\text { Postdecisional } \\
\text { condition }\end{array}$ \\
& mean (SD) & & mean (SD) \\
\hline Number of pros of goal pursuit & $.40(.72)^{* *}$ & & $1.03(1.15)^{* * *}$ \\
Number of cons of goal pursuit & $1.14(1.34)^{*}$ & & $.61(.81)^{* *}$ \\
Relative pro-focus index (\# pros-\# cons) & $-.74(1.70)^{* * *}$ & & $.42(1.43)^{* * * *}$ \\
Number of non-consequences & $1.36(1.35)$ & & $1.24(1.29)$ \\
Total number of thoughts & $2.90(1.82)$ & & $2.88(1.50)$ \\
\hline$* * p<.01$. & & \\
$* \begin{array}{lll}* \\
*\end{array}<.1$. & &
\end{tabular}

transformed), $F(1,85)=8.19, p<.01 ; b=.31, p<.01$. Finally, it was revealed that the effect of decision status condition on goal persistence is partially mediated by participants' relative focus on the pros, $F(2,84)=7.54, p<.01, b_{\text {condition }}=-.91, p<.05, b$ pros $=.30, p<.05$, Sobel $z=2.01, p<.05$.

These results provide additional evidence that the defensive focus on the pros of pursuing the chosen goal contributes to the strengthening effects of postdecisional deliberation on goal commitment. The spontaneous thought stream deliberation procedure employed in this study allowed us to capture pre- and postdecisional participants' natural deliberation tendencies. When not forced to list an equal number of pros and cons, as was the case in Study 2, postdecisional participants distorted the assigned deliberation by generating a greater proportion of pros of goal pursuit, as compared to cons, while there was no difference in the number of overall thoughts or non-consequences they generated.

\section{Effects of self-defensiveness}

To further test our defensive postdecisional deliberation hypothesis we examined whether our predicted effects would be stronger for individuals who are high on self-defensiveness as opposed to individuals who are low on this personal trait. We ran a regression analysis on goal persistence (log transformed), with decisional status, self-defensiveness, and their interaction as independent variables, and whether or not participants have solved anagrams before and whether or not English is their native language as controls, $F(9,77)=4.29, p<.01 ; R^{2}=35 \%$. Results revealed a main effect of decision status, $\mathrm{b}=-.43, p<.01$, and no main effect of self-defensiveness, $b=-.12, p<.60$. Importantly there was a significant interaction between decision status and self-defensiveness, $\mathrm{b}=-.38, p<.05$.

To explore this interaction, we conducted a follow-up spotlight analysis (Aiken \& West, 1991), depicted in Fig. 3. Specifically, we examined the effects of decision status at high and low levels of selfdefensiveness (i.e., one standard deviation above or below the mean). The effect of decision status condition was not significant for individuals low in self-defensiveness $(b=-.11, p<.70)$, suggesting that low self-defensiveness individuals' anagrams persistence did not differ significantly across the two conditions. However, the effect of decision status condition was significant for individuals high in selfdefensiveness $(b=-.74, p<.001)$, suggesting that individuals high in self-defensiveness persisted significantly longer in solving anagrams in the postdecisional, as compared to the predecisional condition.

The current study provides converging evidence for the differential effects of pre- and postdecisional deliberation on goal commitment using a different decision status manipulation and a different indicator of goal commitment. This study also confirmed that postdecisional individuals tend to focus on the pros of goal pursuit, providing further support for the underlying process of defensive postdecisional deliberation. Finally, this study established that the effect of pre- and postdecisional deliberation on goal commitment is moderated by individual differences in selfdefensiveness. Identifying this boundary condition is particularly important because it bolsters support for the proposed underlying process of defensive postdecisional deliberation by showing that the

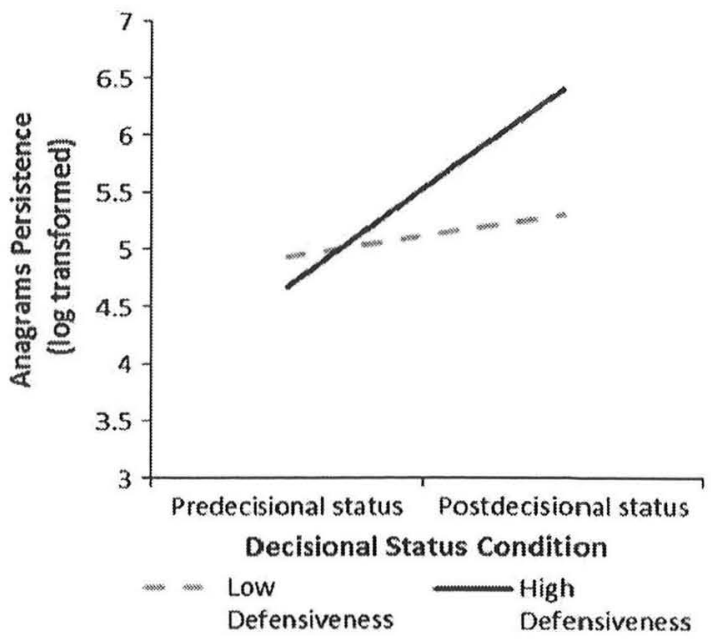

Fig. 3. Study 3: interaction between self-defensiveness and decisional status. High and low levels of self-defensiveness represented at one standard deviation above and below the mean. Log transformations of anagrams persistence.

strengthening effect of postdecisional deliberation on goal persistence was higher for individuals who are naturally high in self-defensiveness.

\section{Study 4: deliberation effects on real-life behavior}

The first three studies presented so far used different operationalizations of goal commitment to provide converging evidence that deliberation assigned in the pre- versus postdecision action phase has distinct effects on goal commitment. We now build on these studies by testing for actual goal adherence in real life. In our Study 4, we vary decisional status by assigning deliberation over two goals, which college students are either decided or undecided about pursuing in everyday life. We show that the respective decrease or increase in goal commitment as a result of assigned deliberation drives pre- and postdecisional individuals' real-life goal adherence. Moreover, we test whether the defensive focus on the pros of goal pursuit exhibited by postdecisional individuals would transfer to their post-deliberation information processing. Specifically, we examine whether their information search is biased in favor of goal achievement-supportive, as opposed to goal achievement-neutral information.

The current study examines whether assigned deliberation would affect college students' real-life pursuit of two recurring goals improving their time-management skills and improving their creativity skills. Based on pilot work, we picked the goal of effective time management as a goal college students are commonly decided to pursue and effective creativity skills as a goal college students are typically still undecided whether to pursue. Specifically, in a pretest we asked 87 undergraduate students ( 32 female; 55 male) to indicate whether they are decided or undecided to pursue 25 goals (6 academic, 4 financial, 4 social, and 11 life-style goals). We also asked participants how important each goal is to them $(1-$ not important at all; 7 - extremely important). Improving one's creativity was the goal for which the highest percentage of participants (87\%; 76 people) indicated that they are undecided whether to pursue, suggesting that improving creativity is not a set goal for most college students. On the other hand, improving one's time management skills was the goal for which the highest percentage of participants $(94 \% ; 82$ people) indicated that they are decided to pursue, suggesting that improving time management is a set goal for most college students. Moreover, there were no significant differences in participants' importance ratings for these two goals $\left(M_{\text {time management }}=5.50\right.$, $\left.S D=1.43 ; M_{\text {creativity }}=5.20, S D=1.82\right), t(85)=1.80, p<.1, d=.18$. 
We expected that depending on people's decisional status, the change in goal commitment resulting from assigned deliberation would predict their likelihood to engage in goal-directed action. Specifically, we expected that post-deliberation increase in goal commitment would make decided individuals more likely to visit and spend time on a website containing information instrumental for achieving the goal they have already decided to pursue (i.e., improving time management skills), whereas post-deliberation decrease in goal commitment will make predecisional individuals less likely to visit and spend time on a website containing information instrumental for achieving the goal they are undecided about pursuing (i.e., improving creativity skills). Moreover, we expect that postdecisional participants visiting the website would spend more time reading goal achievement-supportive information on how they can achieve their chosen goal, as opposed to goal achievement-neutral information on how they can assess their current goal progress. No such difference is expected for predecisional participants visiting the website.

\section{Method}

\section{Participants}

Eighty seven undergraduate students (54 women, 33 men) participated in this study. Participants' age ranged from 17 to 25 years. They received extra course credit or $\$ 5$ gift certificates to a large online retailer for participation. Participants received an email with a link that took them to an online survey containing the study materials.

\section{Design}

Participants were assigned to one of two experimental conditions decided condition, where they were asked to deliberate on the pros and cons of pursuing or not pursuing the goal of improving their time management skills, which was pretested to be a goal most college students are decided on pursuing, and an undecided condition, where they were asked to deliberate on the pros and cons of pursuing or not pursuing the goal of improving their creativity, which was pretested to be a goal most college students are undecided about pursuing. The study was longitudinal, with data collected at two time points. At the first time point, participants' commitment to the goals of improving their time management (creativity) skills was measured and deliberation on the pros and cons of pursuing this goal was assigned. Self-reported commitment to the respective goal was also measured after assigned deliberation. At the second time point, participants were sent a follow-up email containing a link to a web page with information instrumental for achieving their time management or creativity goal, depending on condition. The website provided two types of information - goal achievement-supportive or goal achievement-neutral. As such, some of the links on the website contained information on assessing one's time management (creativity) skills (i.e., goal achievement-neutral information), whereas other links contained information on techniques that can be used to achieve one's goal (i.e., goal achievement-supportive information).

\section{Procedure and materials}

At Time 1, participants were told that they were participating in a study that examines people's decision-making processes and that they would be asked to answer questions about a personal goal and then take part in a decision-making exercise. Participants were first given information as to what time management or creativity is. In the time management condition they were told that time management is a set of principles, practices, skills, tools, and systems working together to help people get more value out of their time and is an important skill to develop in a busy life where multitasking is often required; they were also told that people have varying timemanagement skills and practices and differ in their ability to organize themselves and make the most of their time (see e.g., Zimbardo \& Boyd, 2008). In the creativity condition, they were told that creativity is the ability to produce ideas, work, or products that are novel, original, unexpected, and compelling, and is an important skill to develop as it can help one solve problems in school, on the job, or in daily life, and can lead to new inventions and findings; they were also told that people have varying creativity skills and differ in their ability to engage in creative problem solving and generate innovative ideas (see e.g., Hirt, Devers, \& McCrea, 2008; Sternberg, 1999).

Goal commitment: baseline measure. Participants responded to questions assessing their commitment to the focal goals of improving their time-management or creativity skills. We used the same fiveitem goal commitment scale used in our previous studies, adapted to the goals employed in this study ( $\alpha=.89$; DeShon \& Landis, 1997; $1=$ strongly disagree to $7=$ strongly agree).

Deliberation instructions. We assigned deliberation by asking participants to weigh the pros and cons of pursuing or not pursuing the goal of improving their time management or creativity skills, depending on condition (Gollwitzer \& Kinney, 1989).

Goal commitment: post-deliberation measure. After participants had engaged in the assigned deliberation the same goal commitment scale described above $(\alpha=.96$; DeShon $\&$ Landis, 1997) was applied a second time.

Control measures. Participants' level of time management and creativity skills was measured by asking participants "How do you assess your time management (creativity) skills?" (1 = not good at all; $7=$ excellent). There were no differences in reported skills between participants in the two experimental conditions and between participants who visited and did not visit the website ( $p s>.2$ ).

Behavioral measures. At Time 2, one day after participants completed the online study, they were sent a follow-up email telling them that researchers from their university have put together a website with information on how to improve their time management (creativity) skills, which contains tests to assess their time management (creativity) skills (goal achievement-neutral information) and useful tips on how to improve these and different programs designed to help them develop efficient time management (creativity) strategies (goal achievementsupportive information). They were then given a link that would take them to the website. We had developed the website and set it up so it could track who visited it, which links they browsed, and how much time they spent reading the information presented at each link. The dependent variable was whether participants visited the website (a value of 1 ) or not (a value of 0 ). To tap into postdecisional defensiveness we assessed the time participants spent reading goal achievementneutral versus goal achievement-supportive information.

\section{Results and discussion}

To test our hypothesis we first examined whether decision status affects participants' behavior (i.e., whether they visit the website containing information instrumental to achieving the goal they deliberated on). Next, we tested whether participants' change in goal commitment as a result of deliberation (i.e., the difference between post-deliberation and pre-deliberation goal commitment) mediates these effects. Moreover, we explored how the amount of time participants who visit the website spent reading goal achievementneutral and goal achievement-supportive information differs across the two experimental conditions.

In the decided time management condition, $28 \%$ of the participants visited the website (13 people), whereas in the undecided creativity condition only $9 \%$ visited the website ( 4 people). A logistic regression 
on visiting the website $(1=$ yes; $0=$ no $)$ with decision status condition as the independent variable revealed a significant main effect of decision status on visiting the website $(b=1.29)$, Wald's $\chi^{2}(1$, $N=87)=4.35, p<.05$. Apparently, after assigned deliberation, the likelihood of visiting a website instrumental to achieving a goal one is already decided on pursuing was more than three and a half times greater than visiting a website instrumental to achieving a goal one is still undecided about (odds ratio $=3.64$ )

Next, we tested whether participants' change in goal commitment (i.e., the difference between post-deliberation and pre-deliberation goal commitment) mediates the effects of decision status on visiting the website. First, we ran a regression confirming that decision status condition has a significant effect on the change in goal commitment as a result of deliberation, $F(1,85)=6.73, p<.01 ; b=.37, p<.001$, with decided people reporting an increase in goal commitment as a result of deliberation $(M=.10, S D=.42)$ and undecided people reporting a respective decrease $(M=-.28, S D=.86), t(85)=2.60, p<.01, d=.56$. Next, we ran a logistic regression on visiting the website $(1=$ yes; $0=$ no), with change in goal commitment as a result of deliberation as the predictor variable. In support of our hypothesis, increase in goal commitment had a significant positive effect on visiting the website $(b=1.88)$, Wald's $\chi^{2}(1, N=87)=8.34, p<.01$. Finally, it was revealed that the effect of decision status condition on visiting the website is mediated by participants' change in goal commitment, $\left(b_{\text {condition }}=1.24\right.$, $\left.p<.10, b_{\text {goal commitment change }}=1.96, p<.01\right)$, Wald's $\chi^{2}(1, N=87)=9.74$, $p<.01$, Sobel $z=1.93, p<.05$.

Additionally, to confirm that people who visited the website actually used the provided information, we examined the amount of time they spent on the website and the number of links they browsed. Results revealed that the 13 participants in the decided time management condition, who visited the website spent on average 13.5 min browsing the website and browsed $65 \%$ of the provided links, whereas the 4 participants in the undecided creativity condition, who visited the website, spent on average $5.2 \mathrm{~min}$ on the website and browsed $55 \%$ of the provided links.

We then examined the amount of time participants who visit the website spent reading goal achievement-supportive and goal achievement-neutral information. If postdecisional individuals engage in defensive processing in favor of the chosen goal, it is expected that those who visit the website containing information instrumental to achieving their goal would tend to engage in a biased search for goal achievement-supportive (as opposed to goal achievement-neutral) information. Results confirmed that postdecisional participants visiting the website spent on average significantly longer time reading goalsupportive $(M=574.50 \mathrm{~s}, S D=1,056.15)$ as compared to goal-neutral information $(M=242.58 \mathrm{~s}, S D=575.10), t_{\text {paired }}(12)=2.23, p<.05$, $d=.40$, whereas there was no difference for predecisional individuals $\left(M_{\text {goal-supportive }}=160.28 \mathrm{~s}, S D=276.67 ; M_{\text {goal-neutral }}=155.18 \mathrm{~s}\right.$, $\left.S D=275.55, t_{\text {paired }}(3)=.01, p<.99, d=.04\right)$. These results provide evidence that committed individuals who are assigned balanced deliberation, tend to defensively focus on goal-supportive, rather than goal-neutral information.

The present results provide convergent support for our predictions by assigning decided versus undecided everyday types of goals, assessing goal striving by observing actual goal-directed behavior, and demonstrating the mediating role of goal commitment. Moreover, they showed that postdecisional individuals' defensive focus on the pros of goal pursuit transfers to their post-deliberation information processing. These results provide direct support for our contention that the change in commitment produced by assigned deliberation is consequential, as it was found to affect people's real-life goal adherence. Study 4 thus provides evidence for the real life relevance

\footnotetext{
${ }^{6}$ Additionally, we performed the mediation analyses using post-deliberation goal commitment instead of change in goal commitment and again obtained consistently significant results.
}

of the goal commitment increase caused by assigned postdecisional deliberation. These results have important implications as they suggest that postdecisional individuals' defensive deliberation could be harnessed to strengthen goal commitment and prompt goaldirected behavior in everyday life.

\section{General discussion}

Across the presented set of studies, we found that assigned pre- and postdecisional deliberation can have opposing effects on goal commitment. Our results show that deliberation strengthens goal commitment when individuals deliberate on goals they are already decided on pursuing, but lowers goal commitment when they deliberate on goals about which they are still undecided. In Study 1 we observed the predicted effects of pre- and postdecisional deliberation on goal commitment by assessing commitment via the strength of a person's intention to strive for the goal. In Study 2 we replicated our findings when employing a cognitive-procedural indicator of commitment pertaining to effective goal striving - people's intensity of planning out goal implementation. In the next two studies, rather than letting participants pick goals they are (un)decided about as we did in Studies 1 and 2, we varied decision status: Study 3 allowed pre- versus postdecisional status to develop naturally as the consequence of a manipulated decision environment, and Study 4 employed two goals, which participants are either decided or undecided about pursuing in everyday life. Moreover, we showed that the commitment changes produced by deliberation are consequential. Specifically, Study 3 employed persistence of goal pursuit as an indication of goal commitment, and Study 4 explored striving for everyday life goals. It was observed that increases in commitment as a result of postdecisional deliberation positively affected real-life goal adherence by triggering goal-directed behavior, whereas decreases in commitment as a result of predecisional deliberation failed to do so. Thus our studies rely not only on self-reports, but also provide evidence that the predicted effects extend to actual behavior, which is a particularly valid assessment of goal commitment (Locke et al., 1988; Oettingen et al., 2009).

Moreover, we provide evidence of the process underlying these effects and show that postdecisional deliberation promotes a focus on the pros of pursuing the chosen goal, which has the function to defend and strengthen the already existing goal commitment. Specifically, in Study 2 we used a deliberation procedure that forced participants to list an equal number of pros and cons of goal pursuit and found that forcing postdecisional individuals to deliberate on both the pros and cons leads them to defend their existing goal commitment by overweighing the likelihood of the pros actually occurring. Study 3 used a deliberation procedure assessing spontaneous thoughts allowing us to tap into individuals' natural deliberation tendencies. We showed that postdecisional individuals spontaneously generate more pros of goal pursuit and this defensive focus on the pros boosts their commitment. Furthermore, Study 3 identified a boundary condition for our effects by establishing that the effects of pre- and postdecisional deliberation on goal commitment depend on individual differences in self-defensiveness. This finding bolsters support for the proposed underlying process of defensive postdecisional deliberation by showing that the strengthening effect of postdecisional deliberation on goal persistence is higher for individuals who are naturally high in self-defensiveness. Finally, Study 4 examined whether the defensive focus on the pros of goal pursuit exhibited by postdecisional individuals would transfer to their post-deliberation information processing and showed that postdecisional participants' information search is biased in favor of goal achievement-supportive, as opposed to goal achievement-neutral information. Taken together, our findings serve to highlight the opposing effects that assigned balanced deliberation has on goal commitment in the pre- and postdecision action phases and shed light on the process underlying these effects. 
Implications for mindset theory

Past research on action phase mindsets reviewed earlier has focused on analyzing the features of the associated cognitive orientations (see e.g., Gollwitzer, 2011; Gollwitzer \& Bayer, 1999), but no prior research has examined deliberative mindsets with respect to their effects on goal commitment. This paper fills this gap in the literature by moving away from the study of cognitive dependent variables and assessing the effects of deliberative mindsets on goal commitment.

Some researchers have also found that the effects of deliberative and implemental mindsets can extend to influence behavior (Armor \& Taylor, 2003; Brandstätter \& Frank, 1997; Pösl, 1994). Findings from these studies suggest that the implemental mindset, and not the deliberative one, has positive effects on behavior, as it enhances performance (Armor \& Taylor, 2003), increases the speed of action initiation (Pösl, 1994), and leads to more task persistence (Brandstätter \& Frank, 1997). Results from our Study 4 reveal that deliberating on a decided goal can facilitate behaviors instrumental for achieving the goal, suggesting that postdecisional individuals' defensive deliberation could be harnessed to strengthen goal commitment and prompt goal-directed behavior. As such, the current research extends prior findings by suggesting that the deliberative mindset can also have positive effects on behavior (in situations when the goal can be successfully completed), but only when adopted in the postdecision action phase, when it is defensively partial in favor of the chosen goal.

So when would people engage in postdecisional deliberation in a manner similar to the manipulations we have employed? People may not have to go through the effortful mental exercises we have induced in our experiments; simply trying to find reassurance in regard to personal goal when doubts are experienced because of new information originating from inside (e.g., persistent feelings of low self-efficacy) or outside the person (e.g., negative performance feedback) might trigger an intensive post-decisional deliberation which in turn is likely to strengthen the existing goal commitment. In certain situations, existing commitment may be strengthened by activating postdecisional deliberation via instructions given by others Such an intervention procedure has been developed by Nenkov and colleagues (Nenkov, Inman, \& Hulland, 2008; Nenkov, Inman, Hulland, \& Morrin, 2009); it is based on a simplified deliberative mindset manipulation and induces people to consider the pros and cons of a certain goal.

This research also adds to mindset theory by demonstrating the effects of adopting a deliberative mindset in the postdecision action phase. Although prior research has examined the effects of adopting a deliberative mindset in the predecision action phase with which it is commonly associated, it has not assessed what happens when such a mindset is adopted in the postdecision phase. Our results shed light on this issue and suggest that people do not really fulfill the deliberative mindset when they are in the postdecisional phase. That is, even when instructed to engage in an even-handed consideration of the pros and cons (i.e., assigned balanced deliberation), they tend to focus partially on the pros of goal pursuit despite of the instructions they received. As a result of this, deliberation has opposing effects on goal commitment in the predecision and postdecision phases. Moreover, as discussed in the beginning of this paper, past research has established that individuals in a deliberative mindset analyze desirability-related information impartially and feasibility-related information accurately, whereas implemental mindset participants take a partial perspective in favor of the chosen goal and make optimistic inferences that overestimate its feasibility. The current research builds on these findings to reveal that a deliberative mindset can also trigger a partial processing of desirability-related and feasibility-related information, if adopted in the postdecision action phase.

Prior mindset research has provided some insights into the effects of deliberation on goal commitment. Gollwitzer, Heckhausen, and Ratajczak
(1990) found that asking participants who are still located in the predecision action phase to deliberate on potential change goals (e.g., to switch one's major) can further decrease their perceived proximity to making a change decision. This research speaks to the hypothesis that predecisional deliberation might decrease goal commitment; however, it does not critically test this hypothesis, as perceived proximity to a potential decision cannot confidently be interpreted as a valid and reliable measure of goal commitment. In contrast, the present line of research took a major effort to assess goal commitment in a valid and reliable manner by taking various measures ranging from self-report to planning and actual behaviors. Furthermore, studies by Gagne and Lydon (2001b) found that deliberation over goal decisions participants are still undecided about can initiate defensive processing of information when the goal decisions are related to a current committed relationship. Gagné and Lydon explained this finding by suggesting that the doubt and uncertainty associated with deliberation may pose a threat, as these individuals are already committed to the relationship that the undecided goal relates to. Still, even though Gagne and Lydon (2001b) looked at goals related to a committed relationship (i.e., a relationship with respect to which people were postdecisional), the targeted goals were still unresolved. Thus, their studies did not explicitly analyze the effects of deliberation on goal choices that have already been made (i.e., postdecisional deliberation) - as was done in the present line of research.

\section{Implications for goal commitment theory}

Goal commitment is a central concept in goal-setting theory (Klein, Wesson, Hollenbeck, \& Alge, 1999). Locke et al. (1988) stated that "it is virtually axiomatic that if there is no commitment to goals, then goal setting does not work" (p. 23). Indeed, Klein et al. (1999) established meta-analytically that goal commitment has a positive effect on subsequent performance. Given that goal commitment is an important predictor of performance and goal attainment, and given the construct's overall importance for goal theory, researchers have drawn attention to the importance of examining its antecedents and consequences (e.g., Hollenbeck \& Klein, 1987). The current research contributes to this literature by studying deliberation (both predecisional and postdecisional) as one previously unexamined antecedent of goal commitment.

Past research has shown that different modes of thinking about the future are differentially effective for building strong goal commitment. For example, in their fantasy realization theory of goal setting, Oettingen and her colleagues (e.g., Oettingen \& Thorpe, 2006; Oettingen et al., 2001, 2009) have distinguished between indulging in fantasies, dwelling on negative reality, and mental contrasting as three different modes of thinking that are differentially effective in creating strong goal commitment. These authors studied the implications of contrasting desired positive future outcomes with the negative aspects of present reality for the emergence of goal commitment and proposed that mental contrasting (i.e., the conjoint elaboration of the wished-for future on the one hand, and the present hindrances standing in the way of realizing this future on the other hand) is an important self-regulation strategy that can create binding goals and bring about strong goal commitment. Results from the current set of studies reveal that another mode of thinking about the future - the deliberation of both the anticipated future positive and negative outcomes of goal pursuit - can also serve to strengthen goal commitment: but only for people who have already decided to pursue the goal they are deliberating on.

\section{Implications for goal systems theory}

According to goal systems theory (e.g., Kruglanski et al., 2002; Shah, Kruglanski, \& Friedman, 2003), goal systems consist of mentally represented networks where goals are cognitively associated with their means of attainment. The strength of association between goals and 
means is important as it affects the capability of traffic between these units, which allows the transfer of various motivational properties from one unit to another. Importantly, in goal systems, besides spreading activation from goals to their attached means and vice versa, there can be a transfer of commitment between goals and means in proportion to the strength of their association. Thus, our findings that deliberation after commitment makes people more concerned with implementation (i.e., more committed to implementation) are consistent with goal systems theory's contention that commitment can transfer from goals to means and vice versa, and there is correspondence between commitment to a goal and commitment to its attainment means.

\section{Deliberation in everyday life}

In the past, research has studied the positive effects of adopting a deliberative mindset in the predecision phase it is commonly associated with, and it has pointed to some of its positive effects like facilitating the task of determining which available option is most desirable, while still being feasible (see e.g., Gollwitzer, 1990). The present research, however, revealed that adopting a deliberative mindset in the predecision phase, although helpful in choosing among various wishes and desires, is not beneficial for creating strong, binding goals. On the other hand, adopting a deliberative mindset in the postdecision phase, which was found to be biased in favor of the chosen goal, was shown to strengthen goal commitment. These findings offer important implications for using deliberation to regulate one's goal pursuits in everyday life. The popular notion is that a careful, systematic deliberation is desirable early in the decision process, when all aspects of pursing a goal should be evaluated, but is not desirable once a decision to pursue a goal is already made. Deliberating after having made up one's mind is actually viewed as second-guessing and doubting one's decision. Findings from the current research, however, suggest that "doubting" one's decision by thinking about the pros and cons after one has already committed to pursuing a goal constitutes a useful strategy as it is likely to further reinforce one's commitment and thus increase the probability of goal attainment in situations when the goal can be successfully completed. For example, after people have made an important decision and have selected one house, job, or college from several excellent options, they should be encouraged to deliberate on their choice post hoc, as this postdecision deliberation is expected to strengthen their commitment to the chosen option. It should be noted, however, that whether increased commitment is good or bad for an individual depends on whether the goal in question is worth pursuing and can actually be successfully completed. For example, escalation effects due to increased goal commitment could lead individuals to persist with failing courses of action (e.g., Brockner, 1992), an approach that is not particularly beneficial.

\section{Alternative explanations}

How does the present line of studies relate to research on dissonance theory? Of the many different revisions of dissonance theory, the actionbased model of cognitive dissonance seems most relevant to the present findings. Harmon-Jones and Harmon-Jones (2002) argue that the common spreading of alternatives after a decision between equally attractive alternatives (i.e., seeing the chosen alternative as more attractive than the non-chosen one) does not only serve consistency needs, self-affirmation needs, and the need to avoid feeling personally responsible for producing aversive consequences; it also serves the purpose of smooth acting on the chosen option. In support of this view, these authors report research showing that putting people in an implemental mindset leads to a heightened spreading of attraction of the chosen vs. the non-chosen option. In contrast to this research, the present studies neither modify people's action orientation by creating an implemental mindset (i.e., having them plan out how to act on the chosen goal) nor do they assess the spreading of alternatives. Rather, we requested postdecisional (and predecisional) individuals to deliberate a goal choice and then assessed changes in goal commitment.

Still, one might want to argue that deliberating a goal choice that has been decided might create feelings of dissonance, and that this dissonance might be reduced by strengthening one's commitment to the chosen goal. It is important to note, however, that even though the goal at hand had been chosen freely, the even-handed deliberation of the chosen goal (i.e., the dissonant action) was always assigned to participants in the present studies. Past research shows that the experience of dissonance from one's actions only originates when these actions are freely chosen - assigned actions do not create dissonance as they can easily be explained by referring to the orders one has received (Cooper \& Fazio, 1984). Given that the deliberation studied in the present research was always explicitly assigned to our postdecisional participants, their increases in goal commitment cannot be understood as an act of dissonance reduction.

Another research area seemingly relevant to our findings is work by Tesser and colleagues on the effects of mere thought on attitude polarization (e.g., Tesser \& Conlee, 1975). These authors showed that one's attitude towards an object tends towards greater polarization when one thinks about the attitude object while being cut off from external information about it. The question therefore arises as to whether free thoughts about a chosen goal, rather than systematic deliberation of its pros and cons, could change goal commitment in a similar manner. In answering this question one has to keep in mind that people's positive attitudes toward an object or outcome and their goal commitments to attain desired objects or outcomes are affected by quite different psychological principles. It seems likely therefore that free thoughts about attitude objects, versus desired outcomes that one wants to achieve, would have different consequences. Relevant to this point, extensive research has shown that engaging in thoughts on the features of desired positive outcomes does not intensify, but rather reduces people's commitment to strive for attaining them (e.g., Kappes \& Oettingen, 2011; Kappes, Oettingen, \& Mayer, in press; Oettingen \& Mayer, 2002).

The results of the current set of studies also argue against the contention that mere thought about desired outcomes might already increase respective goal commitment. Specifically, Study 2 provides evidence that it is the overestimation of the likelihood of positive consequences occurring that contributes to the increase in goal commitment, and Study 3 shows that it is the generation of a greater number of positive consequences, not general thoughts, that contributes to the increase in commitment. But are there further systematic forms of thinking about a chosen goal - other than those observed in the present studies - that could increase goal commitment? One may be tempted to assume that asking people to plan out the implementation of the chosen goal (i.e., form implementation intentions; Gollwitzer, 1999) should also increase goal commitment. However, extensive research has shown that even though such planning facilitates goal attainment it does so by automating goal striving, rather than by increasing goal commitment (Gollwitzer \& Sheeran, 2006; Webb \& Sheeran, 2008).

\section{Limitations and future research directions}

The current research provides some evidence that the stage at which deliberation occurs is what drives the obtained effects, as it shows that even when postdecisional individuals are assigned balanced deliberation they still do not engage in an even-handed consideration of pros and cons despite the instructions, and instead tend to defend and strengthen their existing goal commitment by focusing partially on the pros of goal pursuit. Specifically, in Studies 1, 2, and 4, where postdecisional participants were requested to engage in even-handed deliberation, they still showed increased commitment. Meditational analysis confirmed that the reason for this is their focus on the pros of goal pursuit. Future research should continue to build on these findings and further 
disentangle the effects of pre- versus postdecisional stage from the nature (impartial vs. partial) of the deliberation process, by conducting a study with a 2 (decision stage: pre- vs. postdecisional) $\times 2$ (type of deliberation: impartial vs. partial) design.

The current set of studies established that deliberation assigned in the postdecisional stage is partial to the chosen goal, a finding consistent with past research discussed above, which has established the partiality of postdecisional processing (e.g., Beckmann \& Gollwitzer, 1987; Gollwitzer \& Kinney, 1989; Taylor \& Gollwitzer, 1995). An interesting question for future research is to investigate the conditions necessary to induce impartiality postdecisionally.

\section{Conclusion}

The present line of research examined the effects of assigned balanced deliberation not only in the predecision phase, where it has commonly been studied in the past, but also in the postdecision phase, when people are already committed to a chosen goal. The findings from the present set of experiments illustrate that assigned balanced deliberation on a foca goal has opposing effects on subsequent commitment to this goa depending on whether it occurs in the pre- or postdecision action phase. Specifically, assigned balanced deliberation in the predecision phase is characterized by an impartial assessment of the pros and cons, which makes people undetermined and hesitant to commit; to the contrary assigned balanced deliberation in the postdecision phase is characterized by a partial focus on the pros of pursuing the chosen goal, which serves to defend and strengthen commitment to the goal. Together these results make important theoretical contributions to the study of deliberation, goal commitment, and decision making.

\section{References}

Aiken, L. S. \& West, S. G. (1991). Multiple regression: Testing and interpreting interactions Thousand Oaks, CA: Sage.

Armor, D. A., \& Taylor, S. E. (2003). The effects of mindsets on behavior: Self-regulation in deliberative and implemental frames of mind. Personality and Social Psychology Bulletin, 29, 86-95.

Baron, R. M., \& Kenney, D. A. (1986). The moderator-mediator variable distinction in social psychological research: Conceptual, strategic, and statistical considerations. Journal of Personality and Social Psychology, 51, 1173-1182.

Beckmann, J., \& Gollwitzer, P. M. (1987). Deliberative vs. implemental states of mind The issue of impartiality in predecisional and postdecisional information processing. Social Cognition, 5, 259-279.

Brandstätter, V., \& Frank, E. (1997). Bewußtseinslageneffekte auf das Handeln |Mindse effects on acting]. Paper presented at the 6th Tagung der Fachgruppe Sozialpsychologie, Konstanz, Germany.

Brockner, J. (1992). The escalation of commitment to a failing course of action. Academy of Management Review, 17, 39-61.

Brunstein, J. C. (1993). Personal goals and subjective well-being: A longitudinal study. Journal of Personality and Social Psychology, 65, 1061-1070.

Cooper, J. \& Fazio, R. H. (1984). A new look at dissonance theory. In L. Berkowitz (Ed.) Advances in experimental social psychology, Vol. 17. (pp. 229-266)New York: Academic Press.

Crowne, D. P., \& Marlowe, D. (1960). A new scale of social desirability independent of pychopathology. Journal of Consulting Psychology, 24, 349-354.

DeShon, R. P., \& Landis, R. S. (1997). The dimensionality of the Hollenbeck, Williams, and Klein (1989) measure of goal commitment on complex tasks. Organizationa Behavior and Human Decision Processes, 70, 105-116.

Emmons, R. A. (1986). Personal strivings: An approach to personality and subjective well-being. Journal of Personality and Social Psychology, 51, 1058-1068.

Esterling, B. A., Antoni, M. H., Kumar, M., \& Schneiderman, N. (1993). Defensiveness trait anxiety, and Epstein-Barr virus capsid antigen antibody titers in healthy college students. Health Psychology, 12, 32-39.

Evans, R. G. (1979). The relationship of the Marlowe-Crowne scale and its components to defensive preferences. Journal of Personality Assessment, 43, 406-410.

Fujita, K., Gollwitzer, P. M., \& Oettingen, G. (2007). Mindsets and preconscious openmindedness to incidental information. Journal of Experimental Social Psychology, 43, $48-61$.

Gagne, F. M., \& Lydon, J. E. (2001a). Mind-set and close relationships: When bias leads to (in)accurate predictions, Journal of Personality and Social Psychology, 81, 85-96.

Gagne, F. M., \& Lydon, J. E. (2001b). Mind-set and relationship illusions: The moderating effect of domain specificity and relationship commitment. Personality and Social Psychology Bulletin, 9, 1144-1155.

Gendolla, G. H. E., \& Richter, M. (2010). Effort mobilization when the self is involved Some lessons from the cardiovascular system. Review of General Psychology, 14 $212-226$.
Gollwitzer, P. M. (1990). Action phases and mind-sets. In E. T. Higgins \& R.M. Sorrentino Eds.), Handbook of motivation and cognition: Foundations of social behavior, Vol. 2. pp. 53-92)New York: Guilford Press.

Gollwitzer, P. M. (1999). Implementation intentions: Strong effects of simple plans. American Psychologist, 54, 493-503.

Gollwitzer, P. M. (2011). Mindset theory of action phases. In P. Van Lange, A. W. Kruglanski \& E.T. Higgins (Eds.), Handbook of theories of social psychology. London: Sage Publications.

Gollwitzer, P. M., \& Bayer, U. (1999). Deliberative versus implemental mindsets in the control of action. In S. Chaiken \& Y. Trope (Eds.), Dual-process theories in social psychology (pp. 403-422). New York: Guilford Press.

Gollwitzer, P. M., \& Brandstätter, V. (1997). Implementation intentions and effective goal pursuit. Journal of Personality and Social Psychology, 73, 186-199.

Gollwitzer, P. M., Heckhausen, H., \& Ratajczak, H. (1990). From weighing to willing: Approaching a change decision through pre- or postdecisional mentation. Organizational Behavior and Human Decision Processes, 45, 41-65.

Gollwitzer, P. M., Heckhausen, H., \& Steller, B. (1990). Deliberative and implementa mind-sets: Cognitive tuning toward congruous thoughts and information. Journa of Personality and Social Psychology, 59, 1119-1127.

Gollwitzer, P. M., \& Kinney, R. F. (1989). Effects of deliberative and implemental mindsets on illusions of control. Journal of Personality and Social Psychology, 56, 531-542

Gollwitzer, P. M. \& Sheeran, P. (2006). Implementation intentions and goal achievement: A meta-analysis of effects and processes. Advances of Experimental Social Psychology, 38, 69-119.

Harmon-Jones, E., \& Harmon-Jones, C. (2002). Testing the action-based model of cognitive dissonance: The effect of action orientation on postdecisional attitudes. Personality and Social Psychology Bulletin, 28, 711-723.

Harrigan, J. A., Harrigan, K. M., Sale, B. A., \& Rosenthal, R. (1996). Detecting anxiety and defensiveness form visual and auditory cues. Journal of Personality, 64, 675-709.

Heckhausen, H.. \& Gollwitzer, P. M. (1987). Thought contents and cognitive functioning in motivational versus volitional states of mind. Motivation and Emotion, 11,101-120.

Henderson, M. D., de Liver, Y., \& Gollwitzer, P. M. (2008). The effects of an implemental mind-set on attitude strength. Journal of Personality and Social Psychology, 94 396-411.

Hirt, E. R., Devers, E. E., \& McCrea, S. M. (2008). I want to be creative: Exploring the role of hedonic contingency theory in the positive mood-cognitive flexibility link Journal of Personality and Social Psychology, 94, 214-230.

Hollenbeck, J. R., \& Klein, H. J. (1987). Goal commitment and the goal-setting process: Problems, prospects, and proposals for future research. Journal of Applied Psychology, 72, 212-220.

Hollenbeck, J. R., Klein, H. J., O'Leary, A. M., \& Wright, P. M. (1989). Investigation of the construct validity of a self-report measure of goal commitment. Journal of Applied Psychology, 74, 951-956.

Hollenbeck, J. R., Williams, C. L., \& Klein, H. J. (1989). An empirical examination of the antecedents of commitment to difficult goals. Journal of Applied Psychology, 74, 18-23.

Jacobson, L. I., \& Ford, L. H. (1966). Need for approval, defensive denial, and sensitivity to cultural stereotypes. Journal of Personality, 34, 596-609.

Judd, C. M., Kenny, D. A., \& McClelland, G. H. (2001). Estimating and testing mediation and moderation in within-participant designs. Psychological Methods, 6, 115-134.

Kappes, H. B., \& Oettingen, G. (2011). Positive fantasies about idealized futures sap energy. Journal of Experimental Social Psychology, 47, 719-729.

Kappes, H. B., Oettingen, G., \& Mayer, D. (in press). Positive fantasies predict low academic achievement in disadvantaged students. European Journal of Social Psychology.

Klein, H. J., Becker, T. E., \& Meyer, J. P. (2009). Commitment in organizations: Accumulated wisdom and new directions. New York: Routledge.

Klein, H. J., Wesson, M. J., Hollenbeck, J. R., \& Alge, B. J. (1999). Goal commitment and the goal-setting process: Conceptual clarification and empirical synthesis. Journal of Applied Psychology, 84, 885-896.

Kruglanski, A. W., Shah, J. Y., Fishbach, A., Friedman, R., Chun, W. Y., \& Sleeth-Keppler, D. (2002). A theory of goal-systems. In M. Zanna (Ed.), Advances in experimental socia psychology, Vol. 34. (pp. 331-376)New York: Academic Press.

Locke, E. A., Latham, G. P., \& Erez, M. (1988). The determinants of goal commitment. Academy of Management Review, 13, 23-39.

McCabe, B. W. (1989). Ego defensiveness and its relationship to attitudes of registered nurses towards older people. Research in Nursing and Health, 12, 85-91.

Mogg, K., Bradley, B. P., Dixon, C., Fisher, S., Twelftree, H., \& McWilliams, A. (2000). Trait anxiety, defensiveness and selective processing of threat: An investigation using two measures of attentional bias. Personality and Individual Differences, 28, 1063-1077.

Nenkov, G. Y. Inman, J. J., \& Hulland, J. (2008). Considering the future: The conceptualization and measurement of elaboration on potential outcomes. Journal of Consumer Research, 35, 126-141.

Nenkov, G. Y., Inman, J. J., Hulland, J., \& Morrin, M. (2009). The impact of outcome elaboration on susceptibility to contextual and presentation biases. Journal of Marketing Research, 46, 764-776.

Oettingen, G., \& Gollwitzer, P. M. (2001). Goal setting and goal striving. In A. Tesser \& N. Schwarz (Eds.), The Blackwell Handbook of Social Psychology (pp. 329-347). Oxford: Blackwell.

Oettingen, G., \& Mayer, D. (2002). The motivating function of thinking about the future Expectations versus fantasies. Journal of Personality and Social Psychology, 83, 1198-1212.

Oettingen, G., Mayer, D., Sevincer, A. T., Stephens, E. J., Pak, H., \& Hagenah, M. (2009). Mental contrasting and goal commitment: The mediating role of energization. Personality and Social Psychology Bulletin, 35, 608-622.

Oettingen, G., Pak, H., \& Schnetter, K. (2001). Self-regulation of goal-setting: Turnin free fantasies about the future into binding goals. Journal of Personality and Socia Psychology, 80, 736-753. 
Oettingen, G., \& Thorpe, J. (2006). Fantasy realization and the bridging of time. In L. J. Sanna \& E.C. Chang (Eds.), Judgments over time: The interplay of thoughts, feelings, and behaviors (pp. 120-144). New York: Oxford University Press.

Pösl, I. (1994). Wiederaufnahme unterbrochener Handlungen : Effekte der Bewußtseinslagen des Abwägens und Planens [Mindset effects on the resumption of disrupted activities]. Unpublished master's thesis, LMU München, München, Germany.

Reynolds, W. M. (1982). Development of reliable and valid short forms of the Marlowe-Crowne social desirability scale. Journal of Clinical Psychology, 38, 119-125.

Shah, J. Y., Kruglanski, A. W., \& Friedman, R. (2003). Goal systems theory: Integrating the cognitive and motivational aspects of self-regulation. In J. Olson \& M. Zanna (Eds.). The Ontario Symposium on Personality and Social Psychology (pp. 247-275). Hillsdale, NJ: Erlbaum.
Sternberg, R.J. (1999). Handbook of Creativity. Cambridge, UK: Cambridge University Press. Taylor, S. E., \& Gollwitzer, P. M. (1995). Effects of mind-set on positive illusions. Journal of Personality and Social Psychology, 69, 213-226.

Tesser, A., \& Conlee, M. C. (1975). Some effects of time and thought on attitude polarization. Journal of Personality and Social Psychology, 31, 262-270.

Webb, T. L., \& Sheeran, P. (2008). Mechanisms of implementation intention effects: The role of intention, self-efficacy, and accessibility of plan components. British Journal of Social Psychology, 48, 507-523.

Wright, R. A. (2008). Refining the prediction of effort: Brehm's distinction between potential motivation and motivation intensity. Social and Personality Psychology Compass, 2, 682-701.

Zimbardo, P., \& Boyd, J. (2008). The time paradox: The new psychology of time that will change your life. New York: Free Press. 